\title{
A identidade sociocultural do jovem agricultor na vitivinicultura familiar e sua relação com a sucessão rural
}

\author{
The sociocultural identity of the young farmer in family viticulture and \\ its relationship with rural succession \\ Rodrigo Monteiro' ${ }^{1}$, Franklin Peña Mujica' ${ }^{1}$ (1) \\ ${ }^{1}$ Curso de Licenciatura em Sociologia, Universidade de Caxias do Sul (UCS), Caxias do Sul (RS), Brasil. E-mails: \\ rodrigo.monteiro@embrapa.br; fpmujica@ucs.br
}

\begin{abstract}
Como citar: Monteiro, R., \& Mujica, F. P. (2022). A identidade sociocultural do jovem agricultor na vitivinicultura familiar e sua relação com a sucessão rural. Revista de Economia e Sociologia Rural, 60(spe), e235637. https://doi. org/10.1590/1806-9479.2021.235637
\end{abstract}

Resumo: A sucessão rural é um processo fundamental para a agricultura familiar e está diretamente ligada à juventude rural. A opção de dar continuidade à profissão dos pais é resultado de um conjunto de fatores entre os quais a construção de uma identidade de agricultor, a partir de aspectos socioculturais, que é tão importante quanto os aspectos econômicos relacionados à rentabilidade e à segurança financeira. Na Serra Gaúcha, região com altos índices de desenvolvimento humano, a presença de jovens agricultores na vitivinicultura é imprescindível para a sustentabilidade da cultura agrícola e social. A partir do levantamento do perfil de jovens agricultores do município de Bento Gonçalves, Rio Grande do Sul, identificaram-se os fatores que influenciam a construção positiva da identidade social do agricultor familiar, também conhecido como colono. O acesso à educação, cultura, infraestrutura e bens materiais de qualidade, em um processo de socialização mediado pelo trabalho na vitivinicultura familiar, mostrou-se ser importante na decisão dos jovens em continuar morando e trabalhando no meio rural. A participação na gestão da propriedade e a busca de conhecimentos técnicos, formais ou não, também compõem o cenário de estabelecimento da sucessão rural familiar, que envolve tanto jovens homens quanto mulheres, em um processo de reprodução e transformação social.

Palavras-chave: jovens agricultores, agricultura familiar, trabalho, viticultura, socialização, cultura.

\begin{abstract}
The rural succession is a fundamental process to family farming and it is directly linked to the rural youth. The option to continue the parents' profession is a result of many factors such as the construction of an identity of the farmer from socio-cultural aspects that is as important as economic factors linked to profitability and financial security. At Serra Gaúcha, a region with high levels of human development indices, the presence of young farmers in the viticulture is indispensable to agricultural and social culture sustainability. From the survey of young farmers' profiles from Bento Gonçalves, RS, it was possible to identify factors that influence the positive construction of family farmers', as known as a settler. The access to education and culture, quality infrastructure, and material goods, in a socialization process mediated by work in family viticulture proved to be important in young's decision to keep living and working in the countryside. The participation in the property management and the search for technical knowledge, formal or not, also make up the scenario of establishing family rural succession, involving both young men and women, in a process of reproduction and social transformation.
\end{abstract}

Keywords: young farmers, family farming, work, viticulture, socialization, culture.

\section{INTRODUÇÃO}

Os estudos sobre juventude rural, dentro da Sociologia, têm crescido em número e frequência no Brasil, mostrando a importância que a temática tem recebido nas instituições de pesquisa e ensino, sobretudo em universidades. É necessário considerar que o país, por suas dimensões 
continentais, apresenta uma enorme diversidade de ruralidades e, logo, de jovens rurais, sobre os quais diversas compreensões podem ser feitas.

Por exemplo, na região vitivinícola mais tradicional do país, a Serra Gaúcha, o perfil fundiário é de pequenas propriedades que cultivam, principalmente, uvas para processamento - elaboração de vinho e suco - com mão de obra familiar permanente e, em determinados momentos da safra (poda e colheita), com contratação temporária de empregados. Marcada pela colonização italiana, essa região é considerada uma das mais desenvolvidas do Rio Grande do Sul, com altos índices de qualidade de vida, que conciliam os setores da indústria, serviços e agricultura. Segundo Lazzarotto \& Mello (2014), a produção nessa região é realizada em propriedades que, na sua maioria, não ultrapassam a área produtiva de 6 hectares, tendo mão de obra predominantemente familiar, com idade média dos trabalhadores familiares na viticultura de 50 anos, sendo que somente $27,5 \%$ dos moradores das propriedades vitícolas tinham entre 18 e 40 anos de idade. Segundo dados do Instituto Brasileiro de Geografia e Estatística (2010), em Bento Gonçalves, município onde esta pesquisa foi realizada, o Índice de Desenvolvimento Humano (IDH) era de 0,778, o $16^{\circ}$ maior do estado do Rio Grande do Sul e o $145^{\circ}$ do Brasil, em um universo de 5.565 municípios. Bento Gonçalves faz parte da Região Metropolitana da Serra Gaúcha, da qual é o segundo maior município em número de habitantes e PIB, atrás somente da cidade de Caxias do Sul. A população bento-gonçalvense estimada é de 120.454 pessoas, sendo aproximadamente 6\% na zona rural e 94\% na zona urbana (distribuição em 2010), em uma área de 279,069 km², com 92,3\% de taxa de urbanização (Instituto Brasileiro de Geografia e Estatística, 2010). Esses dados mostram a proximidade física e os tênues limites entre a zona rural e a zona urbana do município, constituindo um continuum entre esses "mundos" e seus moradores. Esse conjunto de informações apresenta um panorama instigante sobre a sucessão rural em áreas de produção de uvas de base familiar, em que existe a necessidade de mão de obra intensiva em pequenas propriedades, as quais estão inseridas em um sistema agroindustrial totalmente integrado à zona urbana.

Nessa realidade, a produção agrícola, que até meados do século XX era a principal atividade econômica da região, sofreu forte influência do avanço da urbanização, com impactos positivos e negativos. Entre os que contribuíram para o desenvolvimento, pode-se destacar o maior acesso a tecnologias de produção e informação, bem como a melhoria da infraestrutura no meio rural, também decorrente da ascensão do enoturismo. Por outro lado, percebe-se que as questões políticas e macro e microeconômicas nem sempre favoreceram a agricultura familiar nessa região, onde a relação comercial estabelecida entre os vitivinicultores e as indústrias processadoras é historicamente conflituosa, como foi descrito no trabalho pioneiro de José Vicente Tavares dos Santos (1978) e reforçada em trabalhos posteriores (Farias, 2016; Roese, 2008; Taffarel, 2013), nos quais a submissão do agricultor às indústrias processadoras fica evidente.

O reflexo dessas transformações é ambíguo: por um lado, reproduz uma relação submissa entre agricultor e indústria, ameaçando a continuidade do modelo existente na vitivinicultura comercial na Serra Gaúcha; por outro lado, contribui para o processo da sucessão rural, ou seja, a continuidade da atividade produtiva, por meio da permanência dos jovens rurais na propriedade, fortemente influenciado pela crescente urbanização do meio rural. Conforme identificou Schneider (2009), a existência nessa região de índices significativos de famílias pluriativas (com significativa renda advinda das atividades não agrícolas) é por causa da industrialização, dos baixos custos com mão de obra e da logística favorável. Percebe-se que a maior parte das explicações para o processo de sucessão rural está centrada em aspectos ligados ao sistema produtivo em si, mas acredita-se ser necessário levar em conta aqueles 
relacionados aos fatores socioculturais, por exemplo, a influência que a educação e a percepção dos pais têm sobre o futuro da atividade dos filhos. Da mesma forma, pode-se considerar o grau de escolarização e o tipo de educação formal que os jovens recebem, assim como a rede e a solidez das relações sociais estabelecidas dentro e fora das comunidades rurais, podendo forjar opiniões e visões de mundo e, assim, influenciar diretamente a escolha de permanecer ou não na atividade agropecuária e no meio rural.

Isto posto, o artigo analisará e discutirá o perfil sociocultural e as relações sociais construídas por jovens filhos de viticultores de Bento Gonçalves/RS e sua relação com o processo de sucessão rural na agricultura familiar, a partir de entrevistas semiestruturadas com 20 jovens agricultores. Partiu-se do pressuposto de que a presença de jovens rurais em Bento Gonçalves/ $\mathrm{RS}$, que permanecem na atividade agrícola, está diretamente relacionada à representação positiva sobre o "ser agricultor", construída por seus antecessores e percebida na materialidade cotidiana, decorrente das experiências socioculturais e do acesso à boa infraestrutura.

\section{FUNDAMENTAÇÃO TEÓRICA}

O objeto de estudo da Sociologia Rural não é o oposto do "mundo urbano", e, consequentemente, ela não pode ser vista como a antítese da Sociologia Urbana, pois ambas têm percursos analíticos próprios. Abramovay (2000) afirma que "as cidades não são definidas pela indústria nem o campo pela agricultura" (p. 6) e enfatiza que "o rural não é definido por oposição e sim na sua relação com as cidades" (p. 2). A Sociologia Rural, então, busca compreender o mundo rural, cuja "ruralidade é vista como um fenômeno social e subjetivamente construído, situado muito mais na mente das pessoas do que propriamente enquanto realidade material e objetiva" (Anjos \& Caldas, 2014, p. 57).

Mesmo as comunidades mais isoladas estão inseridas, em maior ou menor grau, no mundo em que as relações sociais se apresentam menos homogêneas. Entretanto, o sociólogo Roland Robertson (2003), em vez do conhecido termo "globalizado", cunhou o conceito de "glocal", em que a globalização institui limites e fronteiras, pois necessita se ajustar às realidades locais, 0 que não é possível ao desprezá-las. Essa "glocalização" é fundamental para o entendimento da relação entre o "urbano" e o "rural" contemporâneos, nos quais os limites, principalmente em função da conectividade, são muito mais tênues que antigamente, mas sem perder suas identidades. Essas diferenças e particularidades fazem parte da discussão sobre as ruralidades, que não são homogêneas porque não são "apenas um setor da economia agrícola, agroindustrial ou semi-agrícola, mas [...] um modo tradicional de viver e sentir, profundamente arraigado na história coletiva" (Rios, 1979, p. 79).

No Brasil, as mudanças econômicas e políticas do período pós-guerra refletiram-se na produção intelectual, que passou à busca da compreensão - e solução - do atraso do meio rural, sobretudo agrícola. Até meados da década de 1970, as pesquisas preocupavam-se com “o papel da agricultura no padrão de acumulação de capital e os mecanismos através dos quais o excedente iria contribuir para assegurar a industrialização e a expansão econômica" (Navarro, 2019, p. 474). Nesse mesmo período, até o final dos anos 1990, houve uma "institucionalização definitiva das Ciências Sociais ditas 'rurais', tendo como pano de fundo a lenta transição entre um rural agrário, ancorado no passado, e a emergência de um país crescentemente dominado pela vida urbana" (Navarro, 2019, p. 475).

A discussão entre o que é rural e urbano trouxe entendimentos sociológicos a fim de desnaturalizar alguns conceitos do senso comum sobre o rural, que o associa a termos depreciativos, como atrasado e rude, decorrentes da hegemonia urbana. Nesse sentido, para 
a compreensão do rural, é necessário conceituá-lo, o que foi feito por Ricardo Abramovay (2000), que sintetizou as principais características do "rural contemporâneo" em três aspectos fundamentais: o primeiro é a relação com a natureza, que é maior no meio rural do que no meio urbano e que, em alguns casos, ainda traz ideias idílicas sobre o rural; o segundo diz respeito à relativa dispersão populacional no meio rural; e o terceiro se refere à dependência (principalmente econômica) do meio rural ao sistema urbano. A socióloga Maria de Nazareth Baudel Wanderley $(2000$, p. 88) acrescenta que "destas relações [de interconhecimento], resultam práticas e representações particulares a respeito do espaço, do tempo, do trabalho, da família etc.". Para esses autores, a ressignificação do rural o aproxima do urbano, superando esquemas dicotômicos, sem descaracterizar as particularidades do campo.

\section{O desenvolvimento da agricultura moderna ou capitalismo agrário}

Além da ressignificação do rural, a modernização da agricultura representou um ponto de inflexão para que a nova agricultura se desenvolvesse sob a égide do capitalismo. Sobre isso, Ricardo Abramovay (1998) explica que a intervenção do Estado, característica do capitalismo monopolista, por meio de organização, subsídios e modernização da agricultura, foi fundamental para o direto desenvolvimento capitalista no mundo, tanto nos países centrais quanto nos periféricos. Posteriormente, os efeitos da modernização também contribuíram para a acumulação de capital, ao gerar reserva de mão de obra para a indústria, resultado dos processos de êxodo rural. Para Wanderley (2000), essa

[...] modernização [...] reforçou [a subordinação da agricultura], ao aprofundar a dependência da produção agrícola aos insumos industriais e ao associá-la cada vez mais aos mercados consumidores urbanos [...]. Consequentemente, as políticas adotadas tinham como prioridade o aumento da eficiência deste setor produtivo, que se expressou na implantação do modelo produtivista da modernização agrícola, cuja base era a adoção de sistemas intensivos de produção e a crescente integração à complexa economia de mercado. (p. 94).

O processo da modernização da agricultura do Brasil aconteceu simultaneamente à chamada "modernização conservadora", após o início do regime militar, em que houve uma mudança capitalista, com crescimento econômico fundamentado na entrada do capital estrangeiro, mas sem alterar as estruturas sociais e fundiárias nem a cultura política tradicional. No pensamento social brasileiro, as análises desenvolveram-se em duas vertentes: em uma, o minifúndio era o responsável pelo atraso das forças produtivas; em outra, "por não serem capitalistas [pela ausência de trabalho assalariado], as relações de produção no campo brasileiro retardavam a expansão do mercado consumidor para os produtos industriais" (Lima, 2005, p. 50). Nesse momento, a agricultura nacional passou a depender do capital estrangeiro por meio da compra de insumos e máquinas - pacotes tecnológicos da Revolução Verde - e da venda da produção de commodities.

\section{Agricultura familiar}

A agricultura passou, portanto, a uma fase capitalista de produção, caracterizada pelo latifúndio, pela monocultura e pelo agronegócio, ao mesmo tempo que a pequena agricultura passou a ser representada pela agricultura familiar. Em "The New Peasantries - Rural Development in times of globalization", van der Ploeg (2018) apresenta um esquema que sintetiza os principais tipos de agricultura aceitos mundialmente, com três grandes categorias: agricultura camponesa, agricultura capitalista e agricultura empresarial, que são diferentes entre si, mas inter-relacionadas. Em oposição à agricultura camponesa, o autor posiciona a agricultura 
capitalista, representada por grandes áreas produtoras, distribuídas em todo o mundo, nas quais a produção é orientada com o objetivo de maximizar o lucro, assemelhando-se a multinacionais que buscam se instalar em regiões onde os custos (financeiros e ambientais) são menores, utilizando trabalho assalariado. Entre esses dois tipos, há a agricultura empresarial, que, ao utilizar crédito e insumos industriais externos à propriedade, associa-se, mesmo que indiretamente, aos capitais financeiro e industrial. Esses agricultores "geralmente emergem de programas de Estado desenhados para 'modernizar' a agricultura” (van der Ploeg, 2018, p. 2), tornando-se dependentes desse sistema.

Essa reflexão mostra a sobreposição de realidades e os limites tênues para categorizar determinados grupos de agricultores, o que permite questionar: "onde se posiciona a agricultura familiar?". Nesse sentido, o autor traz também a discussão sobre as terminologias "agricultura familiar", "pequenas propriedades" e "agricultura camponesa", essa última englobando os outros termos por ser uma realidade multidimensional que diz respeito à produção, à força de trabalho e à gestão da propriedade. Assim, para van der Ploeg (2018),

o conceito de agricultura familiar enfatiza as diferentes relações de propriedade, controle e trabalho. Portanto, [ela] é definida como uma unidade de produção que é gerenciada pela família [...], na qual a maior parte do trabalho (se não todo) é da família e na qual (a maioria) das decisões relacionadas à produção são tomadas pela família. (p. 22).

No Brasil, a agricultura familiar ganhou força e espaço no pensamento social rural na última década do século XX, envolvendo questões políticas e acadêmicas. Até então, como já citado, os trabalhos estavam enfocados na questão da modernização e na transição do agrário para o urbano. Com isso, segundo Weisheimer (2009), o fato de a agricultura familiar assumir uma presença conceitual como objeto sociológico permitiu superar a "falsa dicotomia em torno do caráter tradicional versus moderno ou capitalista versus camponês que caracterizou o debate precedente" (p. 93). Sobre isso, Wanderley (2014) afirma que:

Nos anos 1990, a categoria "agricultura familiar" [...] [diluiu] o conteúdo histórico-político que a palavra "camponês" inspirava, ao mesmo tempo em que se afirmava, pela primeira vez, o reconhecimento da condição de produtor agrícola e uma valoração positiva de suas particularidades. Atualmente, ela é consagrada, não só pelas instituições do Estado, mas também pelos próprios atores sociais, seus beneficiários. (p. S030).

Nesse contexto, políticas públicas voltadas à agricultura familiar passaram a figurar na pauta dos governos, como a criação do Programa Nacional de Fortalecimento da Agricultura Familiar (PRONAF) em 1996 e do Ministério do Desenvolvimento Agrário (MDA) em 1999 - reduzido à categoria de Secretaria em 2016. Um avanço significativo para o Brasil aconteceu em 2006, com a promulgação da Lei n 11.326/06, que estabelece as diretrizes para a formulação da Política Nacional da Agricultura Familiar e Empreendimentos Familiares Rurais, regulamentada pelo Decreto $n^{\circ}$ 9.064/17. A partir dessa lei, mais que acesso ao crédito, os agricultores familiares, silvicultores, aquicultores, extrativistas, pescadores, povos indígenas, quilombolas e povos tradicionais tiveram sua existência reconhecida oficialmente. Dados do Censo Agropecuário do Instituto Brasileiro de Geografia e Estatística (2017), publicados em 2019, mostram que há cerca de 3,9 milhões de estabelecimentos familiares rurais, representando $77 \%$ do número e $23 \%$ da área total nacional, nos quais são empregados aproximadamente 10,1 milhões de pessoas (67\% da mão de obra no campo). Nesse universo, geram-se aproximadamente $23 \%$ do PIB agropecuário nacional.

Na região conhecida como Serra Gaúcha, geograficamente denominada Encosta Superior Nordeste do Rio Grande do Sul, a agricultura familiar remonta ao período da chegada dos imigrantes italianos, no final do século XIX. Segundo a historiadora Assunta de Paris (2006), 
os primeiros colonos ${ }^{1}$ de Bento Gonçalves podiam ser caracterizados como agricultores de subsistência, que vendiam seus excedentes para os grandes centros da época: Porto Alegre, São Leopoldo, Montenegro e São Sebastião do Caí. A partir dessas viagens para trocas comerciais é que os italianos acessaram materiais vegetativos de videira, principalmente da variedade Isabel, que já era cultivada pelos alemães em suas colônias. Na Serra Gaúcha, os imigrantes, ao retomarem questões tradicionais de sua cultura, intensificaram a vitivinicultura, ou seja, o cultivo e o processamento da uva. Passaram a aumentar as áreas de vinhedos, com base na mão de obra familiar que era numerosa, e a expandir a comercialização do vinho para outras regiões, inclusive fora do Rio Grande do Sul. Santos (1978) mostra que, do final do século XIX até meados do século XX, a produção de uva e a elaboração de vinho estavam distribuídas nas propriedades familiares. A partir do final da década de 1960, houve um processo de concentração das indústrias vinícolas, que passaram a processar a maior parte da uva produzida na região, enfraquecendo as chamadas cantinas rurais. Nesse contexto, com a entrada do capital estrangeiro no segmento vitivinícola, os colonos ficaram - e muitos permanecem até hoje - submetidos à burguesia industrial.

Pode-se perceber que a estrutura fundiária familiar dessa região, derivada da Lei de Terras de 1850 e da Lei Provincial de Colonização, apresentadas na análise feita por Vânia Herédia (2007) sobre o Programa de Colonização no Rio Grande do Sul, é bastante diferente do restante do Brasil, que teve o desenvolvimento associado aos latifúndios desde o período colonial e, por isso mesmo, teve influência sobre a estrutura social, refletindo-se até hoje nos processos econômicos e socioculturais da região.

\title{
Juventude rural
}

Os jovens rurais representam o grupo diretamente envolvido no processo de sucessão rural. No Brasil, desde os anos 2000, diversas pesquisas passaram a ter como objeto de estudo (categoria analítica) essa categoria social. São jovens que "saem da condição de apenas filhos de agricultores e tornam-se categoria significativa nos estudos rurais, associada a algumas problemáticas específicas, tais como o êxodo rural e a migração" (Castro et al., 2009). Para tanto, a abordagem geracional do sociólogo Karl Mannheim tem sido utilizada como referência nos estudos sobre juventude rural no Brasil, segundo a perspectiva de que

\begin{abstract}
a juventude é antes de tudo um signo das relações que a sociedade estabelece, simultaneamente, com seu passado e seu futuro. Entre as características dessa categoria, destaca-se a ambivalência típica de sua situação liminar e transitória; a posição subalterna aos adultos na hierarquia social; a conflitividade originada pelo processo de individualização nesta situação liminar e subalterna; a criatividade e capacidade de inovação própria do contato original das novas gerações com a cultura pré-estabelecida. (Weisheimer, 2009, p. 86).
\end{abstract}

Ao estudarem as contribuições acadêmicas sobre a temática da juventude rural no Brasil, Troian \& Breitenbach (2018, p. 790) afirmam que os jovens "ao mesmo tempo em que são agentes de transformação, precisam ser formados e tutelados para encontrar e assumir o seu papel social". Nesse sentido, fatores de natureza individual (depressão e estresse) e fatores socioculturais (família, escola, grupo de amigos e atividades desenvolvidas no tempo livre) são capazes de influenciar os comportamentos juvenis (Vieira, 2004). Barasuol (2016) entende a

\footnotetext{
Segundo Silva (2010), "os imigrantes que se estabeleciam no Rio Grande do Sul eram identificados com a palavra 'colono'. Ser colono, na ótica dos governantes, era equivalente a ser pequeno proprietário agrícola, fixado à terra, adaptado à nacionalidade, respeitador das leis e das autoridades e, sobretudo, ser um produtor de gêneros voltados a 'avolumar as rendas do Estado'. Assim, uma das principais expectativas em relação aos colonos e à colonização era que, definitivamente, eles contribuíssem no sentido de tornar o Rio Grande do Sul o celeiro do país e, para tanto, era necessário que se fixassem à terra e a fizessem produzir." (p. 44).
} 
importância de considerar também os aspectos emocionais que influenciam e motivam a vida dos jovens rurais, os quais devem ser vistos

como atores sociais do meio em que vivem e ainda imersos em um contexto plural e contemporâneo que proporciona uma intensa inter-relação e mobilidade espacial dentro dos diversos espaços (campo-cidade/ rural-urbano), possibilitando de tal forma, ao jovem, rever e reavaliar seus conteúdos simbólicos. (p. 9).

Com relação à juventude rural no estado do Rio Grande do Sul, Nilson Weisheimer (2009), em sua tese de doutorado, apresenta um detalhamento único dessa realidade. A partir de dados primários oriundos de entrevistas com quase 700 jovens em todas as regiões do Rio Grande do Sul, apreende-se que eles podem ser tratados como uma categoria sociológica, sobre a qual diversos processos se desenrolam, sobretudo afeitos à relação entre as representações sociais, identidades culturais e o próprio trabalho. Nessa pesquisa, o autor identificou entre os jovens, além de outros fatores: a baixa autonomia material, a clara divisão sexual do trabalho entre homens e mulheres (agricultura $x$ doméstico), o baixo grau de socialização em atividades de lazer e as representações positivas sobre a atividade de agricultor. Nesse sentido, "a socialização no trabalho agrícola pode ser percebida como o principal instrumento na reprodução social na agricultura familiar, porque produz uma nova geração de agricultores familiares" (Weisheimer, 2009, p. 310). Essa análise, perfeitamente adequada ao nosso entendimento, é reforçada pela afirmação de que

Se há jovens rurais que participam especificamente da produção e da reprodução social da agricultura familiar, ou seja, são socializados no processo de trabalho familiar agrícola, por que não usarmos uma categorização mais precisa, como a de jovem agricultor, em detrimento de outra mais genérica? (Weisheimer, 2005, p. 28).

\section{Sucessão rural}

A produção e a reprodução social da agricultura familiar remetem necessariamente à abordagem da sucessão rural. Segundo dados do Censo Demográfico de 2010, em Bento Gonçalves, $7,7 \%$ do total da população morava na zona rural, sendo $49,1 \%$ de homens e 50,9\% de mulheres. Dados do Censo Agropecuário de 2017 mostram que o número total de estabelecimentos rurais no município era de 1.128 , dos quais somente $183(16 \%)$ estavam sob responsabilidade de pessoas com até 45 anos. No município, onde a área média das propriedades era de 12,67 hectares, a prevalência da agricultura familiar é clara: enquadraramse nessa categoria 76,24\% dos estabelecimentos agropecuários, nos quais 2.302 pessoas (1.637 homens e 665 mulheres) com laços de parentesco com o produtor se ocupavam de atividades produtivas. Nesse universo, pode-se observar que somente os filhos jovens, pois a classificação agrupa cônjuges e outras categorias familiares, são potenciais sucessores para assumir a propriedade rural dos atuais responsáveis.

Dessa forma, pode-se afirmar que a sucessão rural é um processo de transferência de bens materiais e imateriais no meio rural, em que a produção agropecuária ou outras atividades econômicas são responsáveis pela manutenção e reprodução do sistema e das pessoas que dele fazem parte. É por meio da sucessão que os pais passam, gradativamente, a seus descendentes a responsabilidade de conduzir a propriedade e a produção. Essa definição mostra o quão complexo é esse processo, que acontece de diferentes formas segundo a história e a cultura de cada região, principalmente sobre as percepções da atividade econômica e o patrimônio. Não há uma homogeneidade de situações, logo não há fórmulas que determinem como acontece a sucessão rural, mas se sabe que: 
O grau de complexidade de uma decisão depende dos elementos disponíveis para o processo decisório, dos riscos inerentes e das consequências que esta decisão trará para o futuro do decisor. Na agricultura, as decisões cotidianas, de plantio, aplicação de insumos, colheita e mercado, podem adquirir status mais ou menos complexos, dependendo do volume de produção e da representatividade econômica dessa produção para a família. (Panno \& Machado, 2016, p. 220).

A saída dos jovens e o esvaziamento do campo podem decorrer dos elevados custos de produção, do preço de venda dos produtos (abaixo da expectativa) e da escassez de oportunidades e de políticas públicas para incentivar a permanência dos jovens (Zago \& Bordignon, 2012). Outros fatores determinantes para ficar na agricultura ou deixá-la podem ser: o tamanho dos estabelecimentos rurais, as terras insuficientes para o trabalho, as dificuldades de capital financeiro, as oportunidades de trabalho independente da família, o acesso à escolarização, a perspectiva matrimonial com um(a) agricultor(a) e a possibilidade de herdar terra (Weisheimer, 2009, p. 23).

Um dos impactos da falta de sucessão rural são os processos de envelhecimento e masculinização (falta de mulheres) do mundo rural (Anjos \& Caldas, 2014; Costa et al., 2013), que também ocorrem na Serra Gaúcha e são percebidos empiricamente nas famílias rurais. Deve-se considerar também que a sucessão rural em si não diz respeito somente à transferência da propriedade rural e de sua materialidade (bens e benfeitorias), mas também àquilo que historicamente se construiu e que apresenta valor simbólico, tanto para as famílias envolvidas no processo como para a sociedade geral. Entre os diversos problemas que a falta da sucessão rural pode gerar, Matte \& Machado (2017) apresentam:

\begin{abstract}
a não continuidade das propriedades e das atividades produtivas desenvolvidas em seu interior; um crescente esvaziamento demográfico, econômico e cultural das propriedades e das comunidades rurais; aumento da população urbana; masculinização rural (migração feminina superior à masculina); dificuldade de constituição de novas famílias no meio rural (dificuldade de casamentos); falta de mão de obra; envelhecimento da população rural; pais sem amparo na velhice; mercado interno brasileiro diretamente afetado por reduzir a produção de alimentos que o abastecem; expansão de monoculturas (soja, silvicultura); domínio de área por poucos proprietários (monopólio); descaso com as populações que permanecem no meio rural (marginalizadas); entre tantas outras implicações. (p. 135).
\end{abstract}

No processo da sucessão rural, a educação também deve ser levada em conta. Para Pozzebon (2015), o Brasil ainda não valoriza adequadamente a educação do/no campo, pois, além dos processos de extinção e nucleação de escolas rurais, o "conteúdo" trabalhado nas escolas é "urbanocêntrico". Isso significa que ele tende a desvalorizar o conhecimento tradicional e a centralizar a cultura urbana e o "estudo" em si como alternativa às dificuldades e precariedades do mundo rural. Como cita o autor, são comuns as falas "quero que meu filho estude para ser alguém na vida" ou "estude que a caneta é mais leve que a enxada", remetendo à ideia de que o processo de escolarização é melhor que o processo de socialização por meio do trabalho, preconizado nas escolas do campo com base na pedagogia da alternância. Esse entendimento é compartilhado por Spanevello (2008), para quem

a escola acaba por desvalorizar os saberes antigos e os modos de transmissão, modificando a relação dos filhos com o trabalho manual, assim como provoca a divisão do trabalho de educação entre a família e a instituição escolar. (p. 55).

É importante destacar no processo de sucessão rural o protagonismo - ou a falta dele - por parte daqueles que serão os sucessores. Essa característica não é necessariamente imanente a esses indivíduos, mas é construída na relação social entre sucessores e sucedidos, configurando uma socialização no trabalho. De fato, segundo Matt Lobley (2010), essa relação pode, inclusive, alavancar os investimentos na propriedade rural, retroalimentando positivamente o sistema. 
Nesse caso, em um movimento simultâneo, tem-se a (auto)identificação do sucessor e a realização de investimentos que contribuem para sua permanência no sistema. Entretanto, a maior parte dos estudos sobre sucessão rural no Brasil aponta para o que se chama "sucessão tardia", na qual o protagonismo do sucessor não é incentivado, e, mais crítico ainda, é que ele só terá acesso àqueles bens materiais e imateriais da unidade de produção quando os mais velhos morrerem ou perderem a capacidade de gestão.

Outro conceito relacionado ao processo de sucessão rural é a pluriatividade da propriedade e do meio rural, que consiste na execução simultânea de atividades agrícolas e não agrícolas por membros da propriedade rural. Trata-se "de uma estratégia de reprodução social das famílias rurais, que recorrem às atividades externas por diferentes razões (adaptação, reação, estilo de vida), não sendo a pobreza o único fator determinante" (Schneider, 2009, p. 138). Ao buscar tipologias para a pluriatividade rural, esse mesmo autor apresenta quatro possibilidades: 1) pluriatividade tradicional ou camponesa - dentro da propriedade sem visar à mercantilização; 2) pluriatividade intersetorial - resultado da descentralização industrial e rurbanização; 3) pluriatividade de base agrária - prestação e/ou contratação de serviços de agricultores para determinadas práticas de manejo e contratação de serviços sazonais/ safristas; e 4) pluriatividade para-agrícola - agroindustrialização. Essa pluriatividade tem sido percebida como um importante fator de reprodução dos sistemas de agricultura familiar, sendo responsável pela existência de muitos deles.

\section{METODOLOGIA}

A pesquisa foi realizada em metodologia qualitativa exploratória, com amostra não probabilística de 20 jovens agricultores de Bento Gonçalves. A escolha desses jovens foi aleatória, considerando os registros de atendimentos realizados pelos extensionistas rurais do Escritório Municipal da Emater/RS-ASCAR e o fato de esses jovens continuarem trabalhando na agricultura. Para realizar a pesquisa, foi utilizada a técnica de entrevista semiestruturada, considerada uma conversa que, "como forma privilegiada de interação social, está sujeita à mesma dinâmica das relações existentes na própria sociedade" (Minayo, 2008, p. 262).

A entrevista foi realizada na casa dos entrevistados a partir de agendamento via aplicativo de mensagens WhatsApp. Ao chegar ao local, todos os entrevistados foram informados sobre os objetivos da pesquisa e como a entrevista aconteceria, além de assinarem o Termo de Consentimento Livre e Esclarecido. O questionário utilizado para a entrevista, a qual foi gravada para posterior transcrição, consistia em 39 perguntas, organizadas em identificação e dados demográficos do entrevistado, de sua família e do perfil do jovem agricultor: trabalho, educação, cultura, percepção da relação urbano-rural e perspectivas pessoais, sendo que a preferência era ouvir os jovens sem a presença dos pais.

Após a fase de entrevistas, os dados quantitativos foram sistematizados a partir de suas frequências, e as informações qualitativas foram analisadas por meio da análise textual discursiva, segundo a metodologia de Moraes \& Galiazzi (2011). Essa análise compreende a sequência unitarização, categorização e produção do metatexto, permitindo apreender do material oral informações para a compreensão do fenômeno em estudo. $O$ emprego desse tipo de análise trouxe como benefício à pesquisa, apesar da dificuldade em fazê-lo, a construção concomitante da descrição e interpretação como essenciais para a interpretação do fenômeno, a qual segue uma visão hermenêutica de reconstrução de significados com acento na perspectiva dos sujeitos envolvidos na pesquisa (Medeiros \& Amorim, 2017, p. 250). 


\section{RESULTADOS E DISCUSSÃO}

O intervalo etário dos entrevistados (17 a 39 anos), apesar da heterogeneidade, permite classificar todos como jovens, a partir da abordagem geracional de Karl Mannheim, na qual a criatividade e a capacidade de inovação são características da juventude.

Tabela 1: Perfil dos jovens agricultores e suas famílias entrevistados na pesquisa em Bento Gonçalves, 2019.

\begin{tabular}{|c|c|c|c|}
\hline Indicador & Categoria & Frequência absoluta & Percentual \\
\hline \multirow[t]{2}{*}{ Sexo } & Masculino & 16 & $80 \%$ \\
\hline & Feminino & 4 & $20 \%$ \\
\hline \multirow[t]{5}{*}{ Idade } & $15-19$ & 9 & $45 \%$ \\
\hline & $20-25$ & 2 & $10 \%$ \\
\hline & $26-30$ & 3 & $15 \%$ \\
\hline & $31-35$ & 2 & $10 \%$ \\
\hline & $36-40$ & 4 & $20 \%$ \\
\hline \multirow[t]{4}{*}{ Estado civil } & Solteiro(a) & 10 & $50 \%$ \\
\hline & Solteiro(a) com namorada(o) & 3 & $15 \%$ \\
\hline & Casado(a) sem filhos & 1 & $5 \%$ \\
\hline & Casado(a) com filhos & 6 & $30 \%$ \\
\hline \multirow[t]{5}{*}{ Atividade da propriedade } & Somente viticultura & 15 & $75 \%$ \\
\hline & Maior parte viticultura & 2 & $10 \%$ \\
\hline & Maior parte fruticultura & 2 & $10 \%$ \\
\hline & Maior parte horticultura & 1 & $5 \%$ \\
\hline & Presença de agroindústria & 4 & $20 \%$ \\
\hline \multirow[t]{3}{*}{ Mão de obra } & Somente familiar & 6 & $30 \%$ \\
\hline & Empregados temporários & 12 & $60 \%$ \\
\hline & Empregados permanentes & 2 & $10 \%$ \\
\hline \multirow[t]{2}{*}{ Núcleo familiar } & Até 4 pessoas & 12 & $60 \%$ \\
\hline & 5 a 10 pessoas & 8 & $40 \%$ \\
\hline \multirow[t]{3}{*}{ Renda familiar mensal } & 1 a 3 salários mínimos & - & - \\
\hline & 4 a 6 salários mínimos & 3 & $15 \%$ \\
\hline & 7 ou mais salários mínimos & 17 & $85 \%$ \\
\hline
\end{tabular}

*Considerando a moradia e o compartilhamento dos recursos financeiros da propriedade (pais e avós). Fonte: dados das entrevistas feitas pelo autor.

É possível observar na Tabela 1 que a maior parte dos jovens agricultores entrevistados era do sexo masculino (80\%), dos quais $75 \%$ tinham irmãs de diferentes idades e escolaridades, as quais deixaram a propriedade rural para trabalhar na cidade. Apenas $20 \%$ dos entrevistados eram do sexo feminino, dado que corrobora outros trabalhos sobre o processo de masculinização do meio rural, tanto no Brasil quanto na América Latina, segundo Breitenbach \& Corazza (2019) e Sili et al. (2016).

Há muitos fatores que podem explicar a escolha das mulheres de sair da propriedade rural, sendo que um dos mais importantes faz parte inclusive da realidade das que escolhem ficar: o incentivo dos pais. Entre as quatro jovens entrevistadas, todas relataram que os pais não as "chamavam para ir ao pomar" nem compartilhavam as informações das atividades cotidianas, preferindo que elas "ficassem em casa estudando", o que, por outro lado, não as impediu de optar pela agricultura como profissão, tendo que conciliar os estudos, o trabalho na agricultura e os afazeres domésticos.

Ainda na Tabela 1, pode-se perceber que $65 \%$ dos entrevistados eram solteiros e moravam com seus pais e irmãos, ao passo que entre os casados, que representam $35 \%$, somente um não morava no mesmo terreno ou casa que os pais ou sogros (morava na "cidade"), pelo fato de ter constituído família na zona urbana de Bento Gonçalves. Entre os casados, somente uma jovem era casada com agricultor. Chama também a atenção o fato de que a maioria dos cônjuges era de outros municípios ou regiões, consequentemente sem nenhuma relação direta com a comunidade rural, tendo conhecido 
sua(seu) parceira(o) em espaços alternativos, como festas, ou por meio de amigos em comum, fora da comunidade. Mesmo não tendo origem no meio rural, essas pessoas mudaram-se para o meio rural, mas continuam desenvolvendo atividades profissionais fora da propriedade.

Esses dados confirmam as afirmações de Schneider (2009) sobre a pluriatividade para-agrícola, na forma de agroindústrias de processamento, que contribuem para a renda das famílias. É o que se constata no depoimento de duas esposas dos entrevistados, que preferiram trocar o emprego na cidade para cuidar das filhas e aprenderam a trabalhar na viticultura. Segundo os próprios entrevistados, o motivo que também influenciou a tomada de decisão foi o fato de eles não quererem sair da atividade agrícola, por serem os sucessores da família, além das vantagens econômicas e financeiras da escolha. Essa realidade observada no interior de Bento Gonçalves permite afirmar que a interação dos jovens agricultores com os jovens urbanos se dá sem maiores problemas, inclusive porque os relacionamentos afetivos não ficam restritos ao contexto rural, e esse processo vai se tornando cada vez mais comum. Nesse aspecto, cabe ressaltar que, apesar de somente dois jovens já explorarem o enoturismo na propriedade, essa possibilidade foi elencada por outros sete entrevistados, que trabalham somente com viticultura.

Nesse contexto, percebe-se que o trabalho na propriedade está diretamente relacionado à participação efetiva dos jovens como mão de obra na produção. Todos os entrevistados desenvolvem atividades na agricultura de forma integral ou parcial, que é o caso daqueles que ainda estudam. Conforme a Tabela 2, 90\% dos entrevistados participavam da tomada de decisões na propriedade, fosse de forma deliberativa ou consultiva, mostrando que, em Bento Gonçalves, os pais dos jovens consideravam importante a presença deles na gestão da propriedade. Especificamente sobre os $40 \%$ cuja participação era consultiva, a fala comum é que, na maior parte das vezes, os pais ou avós não compartilhavam detalhes do negócio familiar, exceto quando enfrentavam alguma limitação de recursos, da mesma forma que acontecia com os $10 \%$ que eram simplesmente comunicados das decisões, sem opinar no processo. Esse grande percentual de protagonismo dos jovens na tomada de decisões se reflete na frequência daqueles que nunca trabalharam fora ou que já tiveram a experiência e desistiram (70\%).

Tabela 2: O trabalho e a remuneração dos jovens agricultores entrevistados na pesquisa em Bento Gonçalves, 2019.

\begin{tabular}{|c|c|c|c|}
\hline Indicador & Categoria & Frequência absoluta & Percentual \\
\hline \multirow{2}{*}{$\begin{array}{l}\text { Trabalho na } \\
\text { propriedade }\end{array}$} & Integral & 13 & $65 \%$ \\
\hline & Parcial & 7 & $35 \%$ \\
\hline \multirow{3}{*}{$\begin{array}{l}\text { Participação } \\
\text { nas decisões da } \\
\text { propriedade }\end{array}$} & Deliberativo & 10 & $50 \%$ \\
\hline & Consultivo & 8 & $40 \%$ \\
\hline & Não participa & 2 & $10 \%$ \\
\hline \multirow{4}{*}{$\begin{array}{l}\text { Remuneração } \\
\text { pelo trabalho na } \\
\text { propriedade }\end{array}$} & Mensalmente, valor fixo & 2 & $10 \%$ \\
\hline & $\begin{array}{l}\text { Mensalmente, valor } \\
\text { variável }\end{array}$ & 9 & $45 \%$ \\
\hline & $\begin{array}{l}\text { Somente quando pede/ } \\
\text { precisa }\end{array}$ & 9 & $45 \%$ \\
\hline & Não recebe & - & - \\
\hline \multirow{5}{*}{$\begin{array}{l}\text { Trabalho fora da } \\
\text { propriedade }\end{array}$} & Já trabalhou, mas parou & 4 & $20 \%$ \\
\hline & Trabalho fixo & - & - \\
\hline & Trabalho temporário & 1 & $5 \%$ \\
\hline & Pretende trabalhar fora & 5 & $25 \%$ \\
\hline & $\begin{array}{l}\text { Nunca trabalhou e não } \\
\text { pretende trabalhar }\end{array}$ & 10 & $50 \%$ \\
\hline
\end{tabular}

Fonte: dados das entrevistas feitas pelo autor. 
Por outro lado, pode-se observar que, entre os 10 entrevistados menores de 21 anos, 6 deles (60\%) afirmaram ter vontade de exercer alguma atividade fora da agricultura, na forma de trabalho assalariado ou autônomo, porém, assim como todos os outros entrevistados, não gostariam de sair do interior para morar na cidade, ou seja, fariam o deslocamento diário entre zona rural e zona urbana. Isso pode estar relacionado ao perfil etário desses entrevistados, que estão no fim da adolescência, período caracterizado por inconstâncias e dúvidas com relação às escolhas da vida. Porém, os dados de que $45 \%$ dos entrevistados não recebiam remuneração mensal (só recebiam dinheiro quando pediam) podem explicar esse anseio de "trabalhar fora" como assalariado. Sobre a remuneração dos outros jovens, $10 \%$ recebiam remuneração fixa em função de acordo com as cooperativas para quem vendiam a produção, ao passo que os outros $45 \%$ tinham remuneração mensal variada conforme as entradas de recurso, já que cada empresa possuía uma política de pagamento da safra da uva.

Como afirmam Magno et al. (2011), a opção por ficar no meio rural ou sair dele não pode ser explicada somente em termos de trabalho e renda, apesar de essa ser, geralmente, a principal motivação, como observado por outros autores (Foguesatto et al., 2016; Panno \& Machado, 2016). Para tanto, os jovens entrevistados foram questionados sobre aspectos que geralmente não são contemplados em pesquisas, mas que fazem parte do chamado "Capital Cultural", segundo a teoria do sociólogo francês Pierre Bourdieu (1974).

As questões referentes aos processos socioeducativos e de identidade estão apresentadas na Tabela 3, na qual pode se observar o nível de escolarização, em que $20 \%$ dos entrevistados responderam que não concluíram o ensino médio, apesar de declararem que no futuro pretendiam acessar a educação de jovens e adultos. Essa mesma frequência era dos jovens que frequentaram o ensino superior, ainda que não tivessem concluído. Um fato importante a se destacar é que $40 \%$ dos entrevistados frequentaram ou frequentam cursos da área das ciências agrárias (técnico agropecuário e agronomia), confirmando o interesse desses jovens em aplicar os conhecimentos adquiridos nas instituições de ensino na propriedade rural, semelhante aos dados de Cavicchioli et al. (2015) na Itália, e de Breitenbach \& Corazza (2019) no Rio Grande do Sul.

Tabela 3: A construção socioeducativa e da identidade dos jovens agricultores entrevistados na pesquisa em Bento Gonçalves, 2019.

\begin{tabular}{|c|c|c|c|}
\hline Indicador & Categoria & Frequência absoluta & Percentual \\
\hline \multirow[t]{9}{*}{ Escolaridade } & $\begin{array}{l}\text { Ensino fundamental } \\
\text { completo }\end{array}$ & 2 & $10 \%$ \\
\hline & Ensino médio completo & 5 & $25 \%$ \\
\hline & Ensino médio cursando & 3 & $15 \%$ \\
\hline & $\begin{array}{l}\text { Ensino médio } \\
\text { incompleto }\end{array}$ & 2 & $10 \%$ \\
\hline & $\begin{array}{l}\text { Ensino médio técnico } \\
\text { completo }\end{array}$ & 2 & $10 \%$ \\
\hline & $\begin{array}{l}\text { Ensino médio técnico } \\
\text { cursando }\end{array}$ & 2 & $10 \%$ \\
\hline & $\begin{array}{l}\text { Ensino superior } \\
\text { completo }\end{array}$ & 1 & $5 \%$ \\
\hline & $\begin{array}{l}\text { Ensino superior } \\
\text { cursando }\end{array}$ & 2 & $10 \%$ \\
\hline & $\begin{array}{l}\text { Ensino superior } \\
\text { incompleto }\end{array}$ & 1 & $5 \%$ \\
\hline
\end{tabular}


Tabela 3: Continuação...

\begin{tabular}{|c|c|c|c|}
\hline Indicador & Categoria & Frequência absoluta & Percentual \\
\hline \multirow{4}{*}{$\begin{array}{l}\text { Fontes para busca de } \\
\text { informações e notícias }\end{array}$} & Internet e rádio & 6 & $30 \%$ \\
\hline & Internet e televisão & 5 & $25 \%$ \\
\hline & Somente internet & 7 & $35 \%$ \\
\hline & $\begin{array}{l}\text { Internet, rádio e } \\
\text { televisão }\end{array}$ & 2 & $10 \%$ \\
\hline \multirow[t]{5}{*}{ Tipos de redes sociais* } & Facebook & 16 & $80 \%$ \\
\hline & Instagram & 15 & $75 \%$ \\
\hline & WhatsApp & 20 & $100 \%$ \\
\hline & Twitter & 6 & $30 \%$ \\
\hline & Outros & 4 & $20 \%$ \\
\hline \multirow[t]{2}{*}{ Uso das redes sociais } & Várias vezes ao dia & 14 & $70 \%$ \\
\hline & Somente em casa & 6 & $30 \%$ \\
\hline \multirow[t]{5}{*}{$\begin{array}{l}\text { Participação em } \\
\text { grupos sociais* }\end{array}$} & $\begin{array}{l}\text { Grupo na comunidade } \\
\text { (igreja) }\end{array}$ & 2 & $10 \%$ \\
\hline & $\begin{array}{l}\text { Outro tipo de grupo } \\
\text { dentro ou fora } \\
\text { da comunidade } \\
\text { (cooperativa, dança, } \\
\text { futebol, sindicato) }\end{array}$ & 8 & $40 \%$ \\
\hline & $\begin{array}{l}\text { Grupo de amigos da } \\
\text { comunidade }\end{array}$ & 7 & $35 \%$ \\
\hline & $\begin{array}{l}\text { Grupo de amigos de } \\
\text { fora da comunidade }\end{array}$ & 5 & $25 \%$ \\
\hline & Somente família & 4 & $20 \%$ \\
\hline \multirow{5}{*}{$\begin{array}{l}\text { Experiências de } \\
\text { viagem (lazer e } \\
\text { trabalho) }\end{array}$} & Rio Grande do Sul & 7 & $35 \%$ \\
\hline & Região Sul & 6 & $30 \%$ \\
\hline & Outras regiões do Brasil & 3 & $15 \%$ \\
\hline & Brasil e exterior & 4 & $20 \%$ \\
\hline & Nunca viajou & - & - \\
\hline \multirow[t]{4}{*}{ Intenções de viagem } & Região Sul & 4 & $20 \%$ \\
\hline & Outras regiões do Brasil & 5 & $25 \%$ \\
\hline & Brasil e exterior & 9 & $45 \%$ \\
\hline & Não tem intenção & 2 & $10 \%$ \\
\hline \multirow{4}{*}{$\begin{array}{l}\text { Atividades nas horas } \\
\text { livres* }\end{array}$} & Família & 7 & $35 \%$ \\
\hline & Amigos/namorada(o) & 8 & $40 \%$ \\
\hline & $\begin{array}{l}\text { Trabalho paralelo, } \\
\text { estudo ou esporte }\end{array}$ & 6 & $30 \%$ \\
\hline & Descansar em casa & 4 & $20 \%$ \\
\hline
\end{tabular}

* Percentuais ultrapassam 100\% porque os entrevistados podiam elencar mais de uma opção em suas respostas. Fonte: dados das entrevistas feitas pelo autor.

Nas falas dos jovens, percebe-se que todos foram incentivados pelos pais a "terminar os estudos" ou a continuar participando de treinamentos técnicos, independentemente do curso e da opção de ficar ou sair da propriedade rural, mesmo que $65 \%$ dos pais não tivessem concluído o ensino fundamental. Esse é um fato que comprova a mudança de paradigma no meio rural, em que para duas ou mais gerações o incentivo ao estudar não era prioritário. Outro fato que representa uma mudança significativa no perfil do agricultor é a alta porcentagem dos entrevistados que utilizavam a internet como fonte preferencial de informações (65\%), ao passo que a televisão apareceu como complementar à internet para 25\% dos jovens. Mesmo com esse perfil, é interessante destacar que o rádio continua 
sendo importante meio de comunicação no meio rural, sendo acessado por $40 \%$ dos entrevistados.

Sobre a utilização das redes sociais, nota-se que os jovens do meio rural eram tão conectados quanto os do meio urbano: todos utilizavam o WhatsApp, mesmo que somente uma vez ao dia, e a maior parte possuía perfis no Facebook e Instagram (80\% e 75\% respectivamente), com diferentes finalidades, mas principalmente para acesso a informações e lazer. Ressalta-se que os jovens entrevistados, mesmo conectados ao mundo por meio da internet e das redes sociais, parecem não perder sua identidade e foco no local, utilizando essas ferramentas digitais para conhecer e compartilhar projetos e experiências. Como afirmam Viero \& Silveira (2011), as tecnologias de informação e comunicação (TICs) e, por consequência, a internet e as redes sociais não são, por si sós, responsáveis por mudanças significativas na vida e no trabalho dos indivíduos, pois dependem do contexto em que são utilizadas, bem como a importância e a finalidade que a elas são conferidas. Marques et al. (2018) também identificaram essa realidade em um estudo realizado em Tavares, Rio Grande do Sul, onde jovens urbanos, quilombolas, pescadores e rurais utilizavam de forma diferente as redes sociais: enquanto os primeiros priorizavam o lazer, os últimos, para além do entretenimento, valorizavam a profissionalização da atividade produtiva. Os mesmos autores afirmam que "a vida social amparada pela tecnologia e por relações em rede propicia que estes jovens exerçam suas próprias formas de cidadania e sintamse integrados ao que ocorre nos seus contextos locais numa perspectiva global" (p. 89).

É significativo relacionar o uso do WhatsApp como uma das principais formas de socialização desses jovens, os quais participavam de diversos "grupos", nos quais, constantemente, discutiam aspectos da vida e do trabalho. Sobre isso, observa-se que os jovens, em sua maioria, passavam as horas livres em casa ou com a família, reforçando o papel desse indicador na formação do jovem rural, incluindo aí as suas perspectivas de futuro. A falta de espaços de socialização nas comunidades do interior não pareceu incomodar os jovens que, diferentemente da tradição de seus antecessores, não costumavam participar de atividades religiosas (capelas católicas). Sobre esse aspecto, os entrevistados relataram que a convivência no interior estava mais fragmentada e individualizada do que quando eram mais novos, apesar de ainda existir, entre os moradores, a segurança do "todos se conhecem".

Essas percepções sobre o mundo da vida do meio rural e urbano serão analisadas a partir da Tabela 4. O mundo rural no interior de Bento Gonçalves é bastante diferente quando comparado com outras regiões, a partir de suas condições socioeconômicas e a percepção da realidade onde vivem e trabalham, por exemplo, uma das causas da saída dos jovens do meio rural é a busca de melhores condições de vida e de socialização (Breitenbach \& Corazza, 2019; Weisheimer, 2009).

Pode-se observar na Tabela 4 que somente três entrevistados tiveram a experiência de "sair de casa" para trabalhar na cidade e fora da agricultura por períodos que variaram de três a mais de dez anos. Entre os entrevistados, a motivação para retornar ao "campo" tinha a mesma justificativa: de que os pais precisavam de mão de obra e, principalmente, porque identificavam mais vantagens financeiras no trabalho da agricultura em comparação ao trabalho assalariado em empresas da cidade. Porém, cabe ressaltar que, mesmo trabalhando na cidade, dois dos entrevistados continuaram morando na zona rural com os pais. Esse é um fato presente na justificativa "custo menor" para continuar morando no interior, mesmo que se exerça alguma atividade na zona urbana. Isso reforça a percepção 
positiva que os jovens entrevistados tinham do meio rural, já que $100 \%$ deles gostavam de morar no interior.

Tabela 4: A percepção das realidades rural e urbana dos jovens agricultores entrevistados na pesquisa em Bento Gonçalves, 2019.

\begin{tabular}{|c|c|c|c|}
\hline Indicador & $\begin{array}{l}\text { Categorias } \\
\text { identificadas }\end{array}$ & $\begin{array}{l}\text { Frequência } \\
\text { absoluta }\end{array}$ & Percentual \\
\hline \multirow{6}{*}{$\begin{array}{l}\text { Vantagens do meio } \\
\text { rural }^{*}\end{array}$} & Tranquilidade & 15 & $75 \%$ \\
\hline & Liberdade & 7 & $35 \%$ \\
\hline & Custo menor & 4 & $20 \%$ \\
\hline & Trabalho autônomo & 4 & $20 \%$ \\
\hline & $\begin{array}{l}\text { Relações sociais } \\
\text { mais sinceras }\end{array}$ & 5 & $25 \%$ \\
\hline & $\begin{array}{l}\text { Contato com } \\
\text { a natureza e a } \\
\text { paisagem }\end{array}$ & 4 & $20 \%$ \\
\hline \multirow{4}{*}{$\begin{array}{l}\text { Desvantagens do } \\
\text { meio rural }\end{array}$} & Infraestrutura & 8 & $40 \%$ \\
\hline & $\begin{array}{l}\text { Distância até a } \\
\text { cidade }\end{array}$ & 2 & $10 \%$ \\
\hline & $\begin{array}{l}\text { Acesso a recursos } \\
\text { do cotidiano }\end{array}$ & 2 & $10 \%$ \\
\hline & Não há & 8 & $40 \%$ \\
\hline \multirow[t]{4}{*}{$\begin{array}{l}\text { Vantagens do meio } \\
\text { urbano* }\end{array}$} & $\begin{array}{l}\text { Acesso a recursos } \\
\text { do cotidiano } \\
\text { (comércio) }\end{array}$ & 16 & $80 \%$ \\
\hline & Lazer e diversidade & 3 & $15 \%$ \\
\hline & $\begin{array}{l}\text { Trabalho com } \\
\text { horário fixo }\end{array}$ & 2 & $10 \%$ \\
\hline & Não há & 2 & $10 \%$ \\
\hline \multirow[t]{5}{*}{$\begin{array}{l}\text { Desvantagens do } \\
\text { meio urbano }\end{array}$} & $\begin{array}{l}\text { Relações } \\
\text { individualistas }\end{array}$ & 4 & $20 \%$ \\
\hline & Falta de liberdade & 5 & $25 \%$ \\
\hline & Segurança & 3 & $15 \%$ \\
\hline & Ritmo acelerado & 5 & $25 \%$ \\
\hline & Não há & 3 & $15 \%$ \\
\hline \multirow{2}{*}{$\begin{array}{l}\text { Gosta de morar no } \\
\text { interior? }\end{array}$} & $\operatorname{Sim}$ & 20 & $100 \%$ \\
\hline & Não & & - \\
\hline
\end{tabular}

* Percentuais ultrapassam 100\% porque os entrevistados poderiam elencar mais de uma opção em suas respostas. Fonte: dados das entrevistas feitas pelo autor.

Na Tabela 4, nota-se que $40 \%$ dos entrevistados não identificaram desvantagens no meio rural, ao passo que $80 \%$ perceberam a principal vantagem do meio urbano como a facilidade de acesso ao comércio, pois era o que faltava nas comunidades do interior. Isso pode ser por causa da infraestrutura da zona rural de Bento Gonçalves, que é muito diferente da maior parte do Brasil. Por exemplo, entre os entrevistados, o local mais distante estava a $25 \mathrm{~km}$ do centro da cidade, com grande parte do acesso por asfalto. A maioria dos entrevistados tiveram experiências de conhecer lugares e pessoas diferentes, sendo que somente 35\% deles não saíram do estado do Rio Grande do Sul. Entre os entrevistados, era comum a fala de que "lá é grande, bonito, mas aqui é melhor". As intenções de viagem para conhecer o exterior não representam desejo de sair do interior, mas principalmente de reforçar os laços culturais, já que os $45 \%$ que apresentaram 
esse desejo pretendiam conhecer a Europa e os países da América Latina com os quais tinham relação familiar. Além disso, conheciam, por meio da internet, casos de sucesso que podiam ser adaptados à sua realidade, representando mais uma forma de socialização no trabalho.

Analisando essa preferência de morar e trabalhar no meio rural pelos entrevistados, percebese que a tranquilidade e a liberdade do meio rural foram os principais fatores e motivos para permanecer na propriedade rural. Essa relação foi analisada por Bagli (2010), comparando o tempo, os hábitos, as funções, as paisagens e as relações cotidianas no meio rural e no meio urbano.

Assim, as perspectivas futuras e a sucessão rural dos jovens agricultores estão refletidas como na análise feita por Priscilla Bagli, pois, em Bento Gonçalves, os jovens tinham a certeza de que, apesar da intensidade do trabalho na agricultura, seu ritmo de vida e suas relações com a natureza e com as pessoas eram mais "saudáveis" do que as vividas no meio urbano, onde as pessoas eram mais individualistas.

Tabela 5: Perspectivas futuras e a sucessão rural dos jovens agricultores entrevistados na pesquisa em Bento Gonçalves, 2019.

\begin{tabular}{llcc}
\multicolumn{1}{c}{ Indicador } & \multicolumn{1}{c}{$\begin{array}{c}\text { Categorias } \\
\text { identificadas }\end{array}$} & $\begin{array}{c}\text { Frequência } \\
\text { absoluta }\end{array}$ & Percentual \\
\hline $\begin{array}{l}\text { Gostaria de } \\
\text { assumir a gestão } \\
\text { da propriedade }\end{array}$ & Sim & 14 & $70 \%$ \\
Não sei & Não & 6 & $30 \%$ \\
constende & Sim & - & - \\
& Não sei & 14 & $70 \%$ \\
Sonho a ser & Não & 6 & $30 \%$ \\
realizado & Familiar & - & - \\
& Laboral/acadêmico & 2 & $10 \%$ \\
& Material (casa, & 11 & $55 \%$ \\
& veículo...) & 5 & $25 \%$ \\
& Não tem & 2 & $10 \%$ \\
\hline
\end{tabular}

* Os já casados estão incluídos na categoria "Sim". Fonte: dados das entrevistas feitas pelo autor.

Diante dessas perspectivas futuras dos jovens agricultores de Bento Gonçalves, na Tabela 5 percebe-se que $70 \%$ deles desejavam ser - ou já se consideravam - o sucessor da propriedade rural, fato que demonstra uma nova configuração no entendimento da problemática da sucessão rural. Além disso, as perspectivas futuras para a maioria dos entrevistados era constituir família, continuar trabalhando e estudando. Por outro lado, 30\% responderam não saber se desejavam ser os sucessores da atividade, representados pelos mais jovens, que ainda viam o trabalho na agricultura como uma "ajuda" aos pais e não tinham uma ideia definitiva para decidir se ia ser a sua profissão do futuro. A questão da importância do trabalho na vida desses jovens ou da socialização por meio do trabalho (Weisheimer, 2009) pode ser confirmada pela frequência de sonhos ou desejos a serem realizados ligados à produção e à tecnologia em si, diretamente relacionados também à família, instituição-chave da agricultura familiar.

Associada às perspectivas de futuro dos jovens está a representação social construída a partir da percepção da realidade e do significado que representa ser agricultor. Esses dados podem ser observados na Tabela 6, na qual a maioria (55\%) dos jovens entrevistados afirmou ter orgulho de ser denominado "colono", termo que frequentemente tem um sentido pejorativo, pois conota algo negativo. Mesmo tendo sido objeto de preconceito em alguns 
momentos, sobretudo na escola urbana, os jovens agricultores percebem que, atualmente, essa "desvalorização" do colono é menor, pois eles mesmos defendem sua posição diante da população urbana, dada sua proximidade.

Tabela 6: Percepção da realidade dos jovens agricultores entrevistados na pesquisa em Bento Gonçalves, 2019.

\begin{tabular}{llcc}
\multicolumn{1}{c}{ Indicador } & \multicolumn{1}{c}{$\begin{array}{c}\text { Categorias } \\
\text { identificadas }\end{array}$} & Frequência absoluta & Percentual \\
\hline Pessoa modelo & Pais, avós, cônjuge & 9 & $45 \%$ \\
& Outros agricultores & 1 & $5 \%$ \\
& Não tem & 10 & $50 \%$ \\
O que acha do termo & Pejorativo & 2 & $10 \%$ \\
"colono"? & Motivo de orgulho & 11 & $55 \%$ \\
& Indiferente & 7 & $35 \%$ \\
\hline
\end{tabular}

Fonte: dados das entrevistas feitas pelo autor.

A vitivinicultura praticada pela maior parte dos jovens agricultores ocupa posição significativa no enoturismo regional, também configurando, segundo os entrevistados, espaço privilegiado para aproximar e valorizar a agricultura aos turistas, em sua maior parte do meio urbano, o que contribui para a valorização do setor. Acredita-se que o "orgulho de ser colono" também deriva do fato de que quase metade dos entrevistados tinha em seus antecessores (pais e avós) um modelo de pessoa, na qual se espelhavam e a qual admiravam, sobretudo pelo trabalho e conquistas materiais derivadas dele. Nesse sentido, cabe a reflexão feita por Peters (2018) sobre o conceito de habitus do sociólogo Pierre Bourdieu:

ao imbuir o indivíduo de interesses na busca por determinados bens e de habilidades para levar suas ações a cabo, o habitus, quando mobilizado nas práticas dos agentes, contribui para reproduzir ou transformar as estruturas sociais nas quais ele opera. (p. 201).

Essas disposições são adquiridas no processo de socialização, e, conforme observado com os jovens agricultores de Bento Gonçalves, a participação, desde crianças, no processo de trabalho da agricultura, constrói a identidade social do agricultor.

\section{CONCLUSÕES}

A opção pela permanência no meio rural, na forma de agricultor familiar, foi observada entre os 20 jovens de idades entre 17 e 39 anos de diferentes comunidades do interior de Bento Gonçalves, entre os quais havia os que já eram os responsáveis pela propriedade rural, os que estavam na transição para suceder os pais e aqueles que ainda eram coadjuvantes do processo, mas com certa preferência para continuar na agricultura. Os fatores identificados para essa escolha não podem ser atribuídos somente à remuneração, já que nem todos a recebiam regularmente, mas principalmente pela identidade social construída na socialização do trabalho e no acesso às boas condições de infraestrutura. As falas dos jovens agricultores entrevistados comprovam que suas relações sociais, sejam as internas à família e ao meio rural, sejam aquelas com o meio urbano, levaram à percepção das vantagens de continuar na agricultura.

Nesse processo, observou-se a importância do incentivo dos pais à educação, ao trabalho, à liberdade de escolha e ao compartilhamento de experiências no seio familiar. Da mesma forma, percebeu-se, ainda que em menor número, o protagonismo das filhas de agricultores, 
que, buscando profissionalização na área, pretendiam assumir a propriedade dos pais no papel de sucessoras. As facilidades presentes no meio rural de Bento Gonçalves, semelhante ao que é observado na região da Serra Gaúcha como um todo, corrobora as possibilidades de pluriatividade na agricultura familiar, contribuindo para o processo de sucessão rural, no qual a produção de uva com tecnologias adaptadas, associada ao seu processamento ou ao enoturismo, figura nos principais anseios dos jovens agricultores, que buscam "inovar" na atividade. Assim também as vivências dentro dos sistemas de produção familiar e a rotina da vida no meio rural fazem surgir o "orgulho de ser colono", ou pelo menos não ter vergonha de assim ser chamado, representando a continuidade da vitivinicultura familiar da Serra Gaúcha.

Fato é que a ruralidade de Bento Gonçalves é particular, assim como o perfil dos jovens rurais que a compõem; por isso, os resultados da presente pesquisa apontam para possibilidades de aprofundamento do tema, já que estudos sobre sucessão rural sempre levam em conta os diferentes sistemas produtivos. No caso da vitivinicultura, existem diversos tipos de produção e perfis de produtores, desde os familiares individuais, os familiares ligados a cooperativas até os empresariais, que são diferentes objetos de estudo. Com base nos resultados ora obtidos, considerar os aspectos socioeducativos e culturais parece ser uma forma de compreensão ampliada da relação que se estabelece entre gerações no processo de sucessão rural, para além de fatores somente econômicos.

\section{REFERÊNCIAS}

Abramovay, R. (1998). Paradigmas do capitalismo agrário em questão. Campinas: Hucitec.

Abramovay, R. (2000). Funções e medidas da ruralidade no desenvolvimento contemporâneo (Texto para Discussão, No. 702). Rio de Janeiro: IPEA.

Anjos, F. S., \& Caldas, N. V. (2014). Da medida do rural ao rural sob medida. In R. C. Martins (Ed.), Ruralidades, trabalho e meio ambiente (pp. 49-76). São Carlos: EdUFSCar.

Bagli, P. (2010). Rural e Urbano: Harmonia e conflito na cadência da contradição. In M. E. B. Sposito \& A. M. Whitacker (Eds.), Cidade e campo: relações e contradições entre urbano e rural (pp. 81-111). São Paulo: Expressão Popular.

Barasuol, A. (2016). Juventude rural e emoções: fatores subjetivos de valorização do campo (Dissertação de mestrado). Programa de Pós-graduação em Extensão Rural, Universidade Federal de Viçosa, Viçosa.

Bourdieu, P. (1974). A economia das trocas simbólicas. São Paulo: Perspectiva.

Breitenbach, R., \& Corazza, G. (2019). Formação profissional e a relação com a sucessão geracional entre jovens rurais. Revista Latinoamericana de Ciencias Sociales, Niñez y Juventud, 17(2), 1-34. http://dx.doi.org/10.11600/1692715x.17212

Castro, E. G., Martins, M., Almeida, S. L. F., Rodrigues, M. E. B., \& Carvalho, J. G. (2009). Os jovens estão indo embora? Juventude rural e a construção de um ator político. Rio de Janeiro: Mauad.

Cavicchioli, D., Bertoni, D., Tesser, F., \& Frisio, D. G. (2015). What factors encourage intrafamily farm succession in Mountain areas? Mountain Research and Development, 35(2), 152-160. http://dx.doi.org/10.1659/MRD-JOURNAL-D-14-00107.1

Costa, C., Froehlich, J. M., \& Carpes, R. H. (2013). Masculinização rural: uma abordagem a partir da regionalização por sistemas agrários no Rio Grande do Sul. Revista Brasileira de Estudos de Populacao, 30(2), 465-483. http://dx.doi.org/10.1590/S0102-30982013000200007 
Farias, C. V. S. (2016). O papel das instituições na formação e transformação da Vitivinicultura da serra gaúcha: Possibilidades de interpretações do desenvolvimento rural pela Nova economia institucional(Tese de doutorado). Programa de Pós-graduação em Desenvolvimento Rural, Universidade Federal do Rio Grande do Sul, Porto Alegre.

Foguesatto, C. R., Artuzo, F. D., Lago, A., \& Machado, J. A. D. (2016). Fatores relevantes para a tomada de decisão dos jovens no processo de sucessão geracional na agricultura familiar. Revista Paranaense de Desenvolvimento, 37(130), 15-28.

Herédia, V. (2007). A imigração européia no século passado: o Programa de Colonização no Rio Grande do Sul. Scripta Nova. Revista Electrónica de Geografía y Ciencias Sociales, 5. Recuperado em 29 de maio de 2020, de https://revistes.ub.edu/index.php/ScriptaNova/ article/view/335

Instituto Brasileiro de Geografia e Estatística - IBGE. (2010). Censo demográfico. Brasília, DF: IBGE. Instituto Brasileiro de Geografia e Estatística - IBGE. (2017). Censo agropecuário. Brasília, DF: IBGE.

Lazzarotto, J. J., \& Mello, L. M. R. (2014). Panorama da mão de obra familiar na viticultura do Rio Grande do Sul (Comunicado Técnico, No. 63). Embrapa Uva e Vinho.

Lima, E. N. (2005). Novas ruralidades, novas identidades: onde? In R. J. Moreira (Ed.), Identidades sociais: ruralidades no Brasil contemporâneo (pp. 41-65). Rio de Janeiro: DP\&A.

Lobley, M. (2010). Succession in the family farm business. Journal of Farm Management, 13(12), 839-851.

Magno, L., Doula, S. M., \& Pinto, N. M. de A. (2011). La formación para el trabajo en la educación media en Colombia. Revista Latinoamericana de Ciencias Sociales, Niñez y Juventud, 1(9), 305-319.

Marques, J., Toaldo, M., \& Jacks, N. (2018). Juventude e consumo midiático em tempos de convergência: algumas observações. Chasqui. Revista Latinoamericana de Comunicación, (137), 73-91. http://dx.doi.org/10.16921/chasqui.v0i137.3401

Matte, A., \& Machado, J. A. D. (2017). Tomada de decisão e a sucessão na agricultura familiar no Sul do Brasil. Revista de Estudios Sociales, 18(37), 130-151. http://dx.doi.org/10.19093/ res.v18i37.3981

Medeiros, E. A., \& Amorim, G. C. C. (2017). Análise textual discursiva: dispositivo analítico de dados qualitativos para a pesquisa em educação. Laplage em Revista, 3(3), 247-260. http:// dx.doi.org/10.24115/S2446-6220201733385p.247-260

Minayo, M. C. S. (2008). O desafio do conhecimento: pesquisa qualitativa em saúde. São Paulo: Hucitec.

Moraes, R., \& Galiazzi, M. C. (2011). Análise textual discursiva (2. ed.). Ijuí: UNIJUÍ.

Navarro, Z. (2019). Meio século de interpretações sobre o rural brasileiro (1968-2018). Revista de Economia e Sociologia Rural, 57(3), 472-489. http://dx.doi.org/10.1590/1806-9479.2019.219449

Panno, F., \& Machado, J. A. D. (2016). A sucessão em propriedades rurais familiares de Frederico Westphalen/RS: influências e direcionamentos decisórios dos atores. Redes, 21(3), 217-237.

Paris, A. (2006). Memórias: Bento Gonçalves - RS. Bento Gonçalves: Arquivo Histórico Municipal.

Peters, G. (2018). Pierre Bourdieu (1930-2002). In S. S. Telles \& S. L. Oliveira (Eds.), Os Sociólogos: de Auguste Comte a Gilles Lipovetsky (pp. 188-215). Rio de Janeiro: Vozes; Rio de Janeiro: Editora PUC. 
Pozzebon, A. (2015). A inserção socioprofissional dos jovens egressos da Escola Família Agricola de Santa Cruz do Sul no Vale do Rio Pardo, RS: uma contribuição para o desenvolvimento rural(Dissertação de mestrado). Programa de Pós-graduação em Desenvolvimento Rural, Universidade Federal do Rio Grande do Sul, Porto Alegre.

Rios, J. A. (1979). O que é e como surgiu a Sociologia rural? Ciência e Trópico, 7(1), 85-103.

Robertson, R. (2003). Glocalización: tempo-espacio y homogeneidade heterogeneidade. In J. C. Modedeto (Ed.). Cansancio del Leviatán: problemas políticos de la mundialización (pp. 261-284). Espanha: Trotta.

Roese, M. (2008). O Mondovino de cabeça para baixo: as transformações no mercado internacional do vinho e o novo empresariado vinícola. Revista de Sociologia e Politica, 16(31), 71-83. http://dx.doi.org/10.1590/S0104-44782008000200007

Santos, J. V. T. (1978). Colonos do vinho. São Paulo: Hucitec.

Schneider, S. (2009). A pluriatividade no meio rural brasileiro: características e perspectivas para investigação. In H. C. Grammont \& L. Martinez Vale (Eds.). La pluriactividad en el campo latinoamericano (Séria FORO, pp. 132-161). Quito: Ed. Flacso.

Sili, M., Fachelli, S., \& Meiller, A. (2016). Juventud Rural: factores que influyen en el desarollo de la actividad agropecuária. Reflexiones sobre el caso argentino. Revista de Economia e Sociologia Rural, 54(4), 635-652. http://dx.doi.org/10.1590/1234-56781806-94790540403

Silva, M. A. B. (2010). Imigração e imigrantes no Rio Grande do Sul da Primeira República: algunas reflexões sobre o ser colono. História: Debates e Tendências, 9(1), 37-56.

Spanevello, R. M. (2008). A dinâmica sucessória na agricultura familiar (Tese de doutorado). Programa de Pós-graduação em Desenvolvimento Rural, Universidade Federal do Rio Grande do Sul, Porto Alegre.

Taffarel, J. C. (2013). A vitivinicultura relacionada à Indicação de Procedência Farroupilha: perfil, identificação de gargalos e definição de demandas e transferência de tecnologia. Dissertação de mestrado, Programa de Pós-graduação em Biotecnologia e Gestão Vitivinícola, Universidade de Caxias do Sul, Caxias do Sul.

Troian, A., \& Breitenbach, R. (2018). Jovens e juventudes em estudos rurais do Brasil. Interações, 19(4), 789-802. http://dx.doi.org/10.20435/inter.v19i4.1768

van der Ploeg, J. D. (2018). The New Peasantries: rural development in times of globalization (2nd ed.). Londres: Routledge.

Vieira, R. S. (2004). Juventude e sexualidade no contexto (escolar) de assentamentos do Movimento dos Trabalhadores Rurais sem Terra (Dissertação de mestrado). Programa de Pós-graduação em Educação, Universidade Federal de Santa Catarina, Florianópolis.

Viero, V. C., \& Silveira, A. C. M. (2011). Apropriação de tecnologias de informação e comunicação no meio rural brasileiro. Cadernos de Ciência \& Tecnologia, 28(1), 257-277.

Wanderley, M. N. B. (2000). A emergência de uma nova ruralidade nas sociedades modernas avançadas - o "rural" como espaço singular e ator coletivo. Estudos Sociedade e Agricultura, 8(2), 87-145.

Wanderley, M. N. B. (2014). O campesinato brasileiro: uma história de resistência. Revista de Economia e Sociologia Rural, 52(Supl. 1), S025-S044. http://dx.doi.org/10.1590/S010320032014000600002

Weisheimer, N. (2005). Juventudes rurais: mapas de estudos recentes. Brasília: Ministério do Desenvolvimento Agrário. 
Weisheimer, N. (2009). A situação juvenil da agricultura familiar(Tese de doutorado). Programa de Pós-graduação em Sociologia, Universidade Federal do Rio Grande do Sul, Porto Alegre.

Zago, N., \& Bordignon, C. (2012). Juventude rural no contexto da agricultura familiar: migração e investimento nos estudos. In Anais do IX Anped Sul: Seminário de Pesquisa em Educação da Região Sul. Caxias do Sul.

Recebido: Maio 29, 2020.

Aceito: Julho 23, 2021

JEL Classification: N36, J24, R23 